\title{
INDO ALÉM DO ECONOMIZING: O PAPEL DAS REDES SOCIAIS NA APROPRIAÇÃO DE VALOR EM RELAÇÕES COOPERATIVAS
}

BRUNO VARELLA MIRANDA

Mestre pela Faculdade de Economia, Administração e Contabilidade da Universidade de São Paulo (USP).

Pesquisador do Center of Organization Studies da Universidade de São Paulo (Cors-USP). Rua Luciano Gualberto, 908, Cidade Universitária, São Paulo - SP - Brasil - CEP 05508-010

E-mail: bvarella@yahoo.com.br

MARIA SYLVIA MACCHIONE SAES

Doutora em Economia pela Faculdade de Economia, Administração e Contabilidade da

Universidade de São Paulo (USP).

Professora da Faculdade de Economia, Administração e Contabilidade da

Universidade de São Paulo (USP).

Rua Luciano Gualberto, 908, Cidade Universitária, São Paulo - SP - Brasil - CEP 05508-010

E-mail:ssaes@usp.br

É permitido copiar, distribuir, exibir e transmitir essa obra; bem como criar obras derivadas, desde que se confira o devido crédito autoral e se referencie a publicação anterior na RAM (nome da revista, edição, ano e páginas) de forma explícita e clara (mas sem sugerir que a RAM apoia ou endossa o usuário ou o uso feito da obra). Por meio dessa licença, fica explicito a restrição ao uso da obra para fins comerciais. No caso de alteração, transformação ou adaptação dessa obra, você deve distribuir a obra resultante somente nas mesmas condições de licenciamento aqui estabelecidas. 


\section{RESUMO}

Este trabalho, de natureza teórica, investiga o papel das redes sociais para a compreensão da apropriação do valor em relações cooperativas. A perspectiva da governança (WILLIAMSON, I985, I996) adota um cenário composto por agentes atomizados para explicar a estratégia. Nele, é possível aos indivíduos estabelecer ex ante os benefícios de participação em uma relação cooperativa e, assim, mitigar as possibilidades de comportamento oportunista. O presente artigo demonstra que a caracterização dos mercados feita pela perspectiva da governança é imprecisa. Mais especificamente, argumenta que a existência de ativos específicos dificulta a obtenção da informação necessária para a determinação do valor gerado em um esforço cooperativo. Como consequência, é possível que haja o desalinhamento entre as contribuições relativas e as respectivas recompensas nessas relações. Compreender a forma como os agentes econômicos obtêm essa informação e quais as motivações por trás de sua transferência são os objetivos deste trabalho. Para tanto, a contribuição da nova sociologia econômica (GRANOVETTER, I985, 2005; UZZI, I996) é utilizada. As principais conclusões são: I. o hold up não representa o único risco de comportamento oportunista em uma relação cooperativa; 2. a transferência de informações constitui uma dimensão que ajuda a explicar as motivações dos agentes nessas relações; 3. a participação em redes contribui para a redução dos custos de obtenção da informação relevante; 4 . a existência de redes densas explica a transferência gratuita de dados entre os seus membros. O conteúdo desenvolvido nas próximas páginas possibilita uma reflexão acerca da relação entre os indivíduos e o espaço de interação em que realizam intercâmbios. Permite, dessa maneira, um olhar mais realista sobre a arquitetura dos mercados, tema curiosamente pouco estudado pelos economistas. Ademais, fornece ferramentas para a interpretação da existência de padrões heterogêneos de distribuição de valor em relações cooperativas.

\section{PALAVRAS-CHAVE}

Estratégia; Custos de transação; Enraizamento; Oportunismo; Redes. 


\section{INTRODUÇÃO}

Este trabalho parte de uma conhecida afirmação de Oliver Williamson (I99Ia, p. 75), de que, quando se trata de estratégia "entre o economizing e o strategizing, o economizing é muito mais fundamental”. O motivo, argumenta o autor na sequência, é a limitada possibilidade de utilização do strategizing (PORTER, I985, I998), restrita a firmas com poder de mercado. A minimização dos custos de governança, por sua vez, constituiria uma espécie de "lição de casa" para qualquer organização.

De fato, a progressiva compreensão da lógica do economizing tem possibilitado a realização de inúmeros estudos empíricos (SHELANSKI; KLEIN, I995; MACHER; RICHMAN, 2006). A perspectiva da governança (WILLIAMSON, I985, I996) oferece uma hipótese central a ser testada, qual seja: os agentes alinharão as estruturas de governança às características da transação, especialmente o grau de especificidade dos ativos, de modo a minimizar os custos de transação incorridos.

Diversas questões, porém, permanecem sem resposta. A perspectiva da governança, por exemplo, não oferece uma explicação para a existência de padrões heterogêneos de distribuição de valor em relações cooperativas. Seguindo o exemplo de autores marginalistas como John Bates Clark (ELLIOTT, 2007) ou neoinstitucionalistas como Alchian e Demsetz (I972), admite-se que a recompensa obtida após a participação em uma atividade econômica corresponderá à produtividade individual. Não por acaso, seus principais estudos assumem que os agentes são plenamente capazes de identificar as recompensas derivadas da participação em um esforço cooperativo (WILLIAMSON, I99Ib; KLEIN, 2002).

Inspirado na contribuição da nova sociologia econômica, o presente artigo fornece uma interpretação alternativa para o processo de apropriação de valor descrito pela perspectiva da governança. Abandonando a pressuposição de que os indivíduos sempre conseguirão determinar suas próprias recompensas, introduz a noção de enraizamento ${ }^{2}$ (GRANOVETTER, I985, 2005; UZZI, I996) para explicar a distribuição do valor gerado em relações cooperativas. Em especial, este trabalho descreve a importância das redes para a minimização dos custos de descoberta dos preços relevantes (COASE, I937).

No original: "between economizing and strategizing, economizing is much more fundamental".

Inexiste consenso, na literatura em português, acerca da tradução para o termo embeddedness. Coexistem duas denominações, a primeira delas aqui adotada, quais sejam: enraizamento (VINHA, 200I; WILKINSON, I999; KIRCHBAUM; IWAI, 20II) e imersão (ABRAMOVAY, 2004, 2005). Block (200I) oferece uma explicação para a origem da ideia de embeddedness na obra de Karl Polanyi. 
O argumento central é o de que é impossível compreender a apropriação de valor por meio da perspectiva da governança sem que sejam incorporadas as ideias trazidas pela nova sociologia econômica³. Nesse sentido, o uso de estratégias desvinculadas de uma lógica estritamente econômica contribui diretamente para a determinação dos resultados colhidos pelos agentes. Quando se tem em conta a hipótese da existência de custos de transação positivos, a participação em uma rede pode explicar não apenas a identificação de oportunidades de negócio (UZZI, I996), como também a capacidade de determinar a quase renda derivada de um esforço cooperativo.

A seguir, apresenta-se uma discussão acerca das implicações da lógica do economizing para o estudo da estratégia. Na sequência, discute-se o processo de evolução da expressão "custo de transação" e suas consequências para a análise da apropriação de valor em relações cooperativas. Depois, apontam-se a contribuição que a ideia de enraizamento oferece à perspectiva da governança e o papel das redes para a minimização dos custos de obtenção de informação.

\section{A Lógica do eCONOMIzIng e A ESTRATÉGIA}

A pesquisa em estratégia se concentra na busca de explicações para a criação e a captura de valor econômico. É interessante notar que a perspectiva da governança não apresenta uma resposta definitiva para nenhum desses desafios. Na realidade, a hipótese do alinhamento eficiente fornece uma interpretação para a proteção ex post do valor gerado em uma relação cooperativa (KLEIN; CRAWFORD; ALCHIAN, I978; WILLIAMSON, 2005). Não esclarece, entretanto, os antecedentes da cooperação produtiva ou a heterogeneidade nos padrões de apropriação de valor.

O foco na proteção ex post deriva da concepção de um cenário em que as partes sabem exatamente o que está em jogo em uma relação cooperativa. Williamson (I99Ia, p. 8I) salienta que a escolha da estrutura de governança e o acordo acerca do preço de transferência dos ativos são decididos simultaneamente. Não por acaso, a principal preocupação da perspectiva da governança está no hold up, ou seja, a quebra contratual motivada pelo comportamento oportunista.

Justiça seja feita, a perspectiva da governança, ao pressupor a capacidade de pleno dimensionamento das contribuições individuais em um esforço cooperativo, considera o problema da apropriação do valor em relações estáveis uma questão bem resolvida. Ver, por exemplo, os trabalhos de Williamson (I99Ib) e Menard (I996). 
Nada é dito, porém, sobre os motivos que levariam dois indivíduos a se aproximar e decidir pelo estabelecimento de uma relação cooperativa (NICKERSON; YEN, 2OII). Em outras palavras, a perspectiva da governança assume que os agentes econômicos são igualmente capazes de identificar oportunidades de negócio. Os dois pressupostos comportamentais integrados à análise, o oportunismo e a racionalidade limitada (WILLIAMSON, I985), não desafiam essa hipótese. Ambos são usados, em grande medida, para justificar o risco de hold up.

O cenário em que a perspectiva da governança é construída tampouco permite a plena compreensão da lógica da criação e da apropriação de valor. Semelhante ao espaço de interação descrito pela economia neoclássica, este se caracteriza por seu caráter abstrato. Embora se apoie na existência de custos de transação, Williamson (2002, p. I79) refuta a hipótese de Coase (I937, p. 390) de que o acesso dos agentes econômicos à informação disponibilizada pelo mecanismo de preços não é óbvio.

É natural que, em um mundo assim descrito, os gastos com a governança assumam o protagonismo; se todos sabem o melhor a ser feito, só resta fazê-lo com eficiência. Evidência dessa realidade é a avaliação de Williamson (I99ıa, p. 78) acerca dos regimes socialistas. A referência a Oskar Lange busca associar a derrocada soviética aos excessivos custos de sua burocracia ${ }^{4}$. No plano privado, a conclusão é semelhante: a minimização dos custos de governança constitui "a melhor estratégia" (WILLIAMSON, I991a, p. 76).

Qual é o significado prático, então, da adoção de uma estratégia baseada exclusivamente na lógica do economizing? De acordo com Williamson (I985, I996), o estabelecimento de um arranjo organizacional alternativo se deve à necessidade de proteção de investimentos idiossincráticos. Quando for necessária a sua realização para o aproveitamento de uma oportunidade de negócio, garantias devem ser dadas. A adoção de um contrato, nesse sentido, significa o compromisso de que as partes manterão as promessas feitas no início da relação cooperativa.

A caracterização de um investimento idiossincrático, porém, pouco revela acerca das características de um mercado. Afinal, o grau de especificidade do ativo se relaciona ao número de agentes interessados em sua aquisição. Se, para a perspectiva da governança, um mercado é incapaz de oferecer alternativas em caso de comportamento oportunista, certamente isso não se relaciona a uma deficiência estrutural. Ora, não há nada mais que o mecanismo de preços possa oferecer às partes além do preço.

4 O argumento de Lange (apud WILLIAMSON, I99ra, p. 78, tradução nossa), é o seguinte: "O real perigo para o socialismo é a burocratização da rotina econômica, e não a impossibilidade de lidar com o problema da alocação de recursos". 
De qualquer maneira, a hipótese do alinhamento eficiente acaba fornecendo uma solução para todos os problemas descritos pela perspectiva da governança (GRANOVETTER, I985). Mitigados os riscos de comportamento oportunista, nada há o que temer quanto à captura de valor. Mesmo eventuais quebras contratuais podem ser justificadas sob a ótica da eficiência (KLEIN, 2002), de modo que o economizing passa a ser não apenas a melhor estratégia, mas também a única. De fato, estudos empíricos inspirados na lógica da perspectiva da governança, como o de Arruñada (2002), passam exatamente essa impressão ao leitor5.

O que aconteceria, no entanto, se os mercados, espaços de interação entre os agentes econômicos, não tivessem as características descritas pela perspectiva da governança? O objetivo das próximas duas seções é discutir essa pergunta. Conforme se verá, a lógica do economizing é suficiente para explicar a apropriação de valor apenas quando hipóteses heroicas são assumidas. A própria definição da expressão "custo de transação", da mesma forma, é afetada quando uma avaliação crítica dos mercados é realizada.

\section{A EVOLUÇÃO DA IDEIA DE CUSTO DE TRANSAÇÃO}

Publicado no final da década de I930, o artigo "The nature of the firm" (COASE, I937) é considerado o trabalho que introduz a noção de custo de transação na literatura econômica. Levaria algum tempo, no entanto, até que o uso da expressão se disseminasse. É apenas na década de I960, após Coase apresentar "The problem of social cost", que suas ideias seriam incorporadas por outros economistas. Textos como os de Arrow (I969), Alchian e Demsetz (I972) e Stigler (I967) exemplificam esse processo.

Desde os primórdios, a análise baseada na existência de custos de transação se caracteriza pela diversidade de interpretações para o legado coasiano. Já nos anos I970, época em que o neoinstitucionalismo econômico começa a ganhar espaço, Fischer (I977, p. 322) critica o caráter vago dessa noção. Mesmo entre os autores identificados com a chamada Nova Economia Institucional, é notável o contraste quando comparadas as suas contribuições.

Arruñada (2002), ao analisar as relações entre os grandes varejistas e seus fornecedores na Espanha, sugere que aqueles teriam um papel semelhante ao de "tribunais de primeira instância", resolvendo disputas de forma menos dispendiosa. Seu principal argumento é que a atuação dos varejistas seria consistente com a busca de eficiência na governança do relacionamento bilateral, não se observando, ali, o uso de poder de barganha. 
A diversidade encontrada nas interpretações para a expressão "custo de transação" se deve, em grande medida, à sua natureza. Essa noção só pode ser justificada a partir da verificação de precondições específicas. A existência de custos de transação positivos deriva do cenário escolhido pelo cientista social; em outras palavras, sua relevância resulta da caracterização dos agentes econômicos e do espaço de interação em que realizam trocas. Nos mercados descritos pela microeconomia neoclássica, por exemplo, essa discussão faz pouco sentido.

Independentemente da interpretação adotada, voltar às origens é fundamental. Embora Coase (1937, p. 390) não tenha definido com exatidão os chamados "custos para a utilização do mecanismo de preços", relaciona-os à descoberta dos preços relevantes e à negociação e à conclusão dos contratos. A coordenação consciente emergiria sempre que economizasse recursos. A existência da firma, dessa maneira, seria uma alternativa eficiente em um mundo em que o uso da "mão invisível" não é gratuito.

Ao associar a firma à busca por eficiência, Coase (1937) se afasta da visão de seus contemporâneos. Para autores como Robinson (I933) e Kaldor (I934), era a busca por lucros extraordinários o que motivava a sua existência. Desde então, proliferaram as interpretações da firma baseadas no argumento coasiano, sendo a perspectiva da governança uma dessas abordagens. Definiu-se também uma clara preferência pela associação entre os custos de transação e a instituição de relações contratuais.

O aprofundamento dessa visão se deve, em grande parte, ao trabalho de Klein, Crawford e Alchian (I978). Nele, a existência da firma se relaciona a um caso específico, qual seja: a realização de investimentos idiossincráticos. A integração vertical emergiria como uma resposta ao risco de expopriação da quase renda derivada da posse de um ativo específico ${ }^{6}$. A especialização produtiva assume o protagonismo na explicação da coordenação consciente.

Embora façam referência ao legado coasiano, Klein, Crawford e Alchian (I978) argumentam que a decisão de instituir uma firma vai além da prescrição de "The nature of the firm". Se é importante minimizar os gastos de negociação e de conclusão contratual, não se deve esquecer o custo derivado da garantia dos acordos formais. Em consequência, a discussão ali proposta se concentra nas ações dedicadas a verificar o cumprimento ex post dos contratos, algo que contrasta com a contribuição de Coase? .

6 De acordo com Klein, Crawford e Alchian (I978, p. 298), a existência da quase renda resulta da realização de investimentos específicos, correspondendo à diferença entre o valor do ativo na finalidade que motivou a especialização produtiva e o seu melhor uso alternativo.

7 Klein, Crawford e Alchian (1978) também apontam a existência de custos de informação e de transação para a obtenção de acordos, especificando-os como resultantes do processo de descoberta dos custos e da receita real, além das discussões acerca da divisão dos lucros. Eventuais esforços de minimização desses custos, porém, não são abordados ao longo do trabalho. 
Nas décadas seguintes, a consolidação da perspectiva da governança se dá com a adoção de uma visão semelhante à encontrada em Klein, Crawford e Alchian (1978). Para tanto, hipóteses heroicas são assumidas. Assume-se, por exemplo, que os agentes econômicos são plenamente capazes de delimitar a quase renda derivada da especialização produtiva (KLEIN, 2002; WILLIAMSON, I99Ib). Implicitamente, prevalece a pressuposição de que, ao produzir um dado ativo, um indivíduo é também o mais capacitado a determinar o seu valor (CHEUNG, i983, p. 7).

É sobre essas bases que Williamson (1985, 1996) constrói a sua teoria. A adição do pressuposto comportamental do oportunismo, no entanto, adiciona certo dramatismo à narrativa. Afinal, se, por um lado os indivíduos são capazes de determinar aquilo que está em jogo em uma relação cooperativa, podem, por outro, usar essa informação em benefício próprio. Quebras de compromisso, assim, seriam esperadas quando tal comportamento conviesse a uma das partes.

A adoção do oportunismo como um dos pilares da perspectiva da governança acarretaria enorme polêmica. Nos últimos vinte e cinco anos, muito foi escrito acerca da conveniência do uso desse pressuposto (GHOSHAL, 2005; GHOSHAL; MORAN, I996; WILLIAMSON, I993a, I993b). Entre as críticas, chama a atenção a rápida resposta de Granovetter (1985), transformada posteriormente no manifesto fundador da nova sociologia econômica.

\section{CUSTOS DE TRANSAÇÃO E A APROPRIAÇÃO DE VALOR}

Denominados "custos de utilização do mecanismo de preços", os gastos decorrentes da realização de transações são originalmente divididos por Coase (I937) em: I. aqueles ligados à descoberta dos preços relevantes e 2. custos derivados da negociação e da conclusão contratual. Conforme visto até aqui, a hipótese de que nem todos os agentes têm acesso aos preços relevantes foi negligenciada ao longo do tempo. Prevaleceu a preocupação com os gastos relativos à formatação e à garantia dos contratos.

Williamson (2002, p. I79) argumenta que a observação de Coase acerca dos custos de descoberta dos preços relevantes não sobrevive à análise institucional comparativa. De fato, a concepção de mercado adotada pela perspectiva da governança impossibilita a avaliação dessa hipótese. Sob a lógica do alinhamento eficiente, a organização econômica corresponde ao cumprimento de promessas, cujos detalhes ambas as partes são capazes de checar (MIRANDA; SAES, 2OII). 
Um olhar em direção à possível origem dos custos de descoberta dos preços relevantes, porém, é revelador. Essa categoria dos custos de transação se relaciona à forma como os indivíduos se inserem no espaço de interação usado para o intercâmbio, ou seja, à apropriação de informações geradas graças à existência dos mercados. A perspectiva da governança, ao ambientar a sua análise em um ambiente caracterizado pela abstração e pela atomização de seus participantes, ignora essa realidade.

Mais especificamente, a adoção de uma concepção abstrata dos mercados leva a perspectiva da governança a desconsiderar elementos do cenário ao qual se propõe analisar. Se investimentos específicos, por um lado, originam uma quase renda decorrente da especialização produtiva, exigem, por outro, esforços adicionais para o seu dimensionamento. Afinal, identificar as recompensas derivadas da participação em uma relação cooperativa exige o dispêndio de recursos.

Para entender melhor essa lógica, é preciso observar o próprio funcionamento dos mercados. Por um lado, a ideia da "mão invísivel", embora dotada de forte apelo, não esconde o fato de que a adaptação autônoma, possível por causa da existência de algo como o mecanismo de preços, exige o estabelecimento de uma considerável estrutura burocrática. Mesmo aqueles mercados caracterizados por um padrão de funcionamento semelhante ao modelo de concorrência perfeita não escapam dessa realidade.

A existência de múltiplas alternativas organizacionais para a alocação dos recursos, por outro lado, não implica o abandono da informação relativa aos preços. Conforme lembra Williamson (2002, p. I75), o problema da organização econômica não deve ser descrito como um dilema entre mercados e hierarquias, mas sim relacionando essas duas opções. Estudar a coordenação consciente, assim, não implica a divisão entre relações em que o preço dita a alocação e outras em que esse dado nada tem a acrescentar.

Esse argumento é facilitado quando contextualizado. Veja-se o exemplo de qualquer mercado commodity, como aqueles organizados em torno da existência de uma bolsa de valores. Ali, a reunião de milhões de interessados em torno de ativos homogêneos permite o estabelecimento e a manutenção de uma estrutura burocrática considerável. Graças ao trabalho de inúmeras "mãos visíveis", os dados relativos aos preços relevantes são disponibilizados aos agentes, que transacionam em um mercado caracterizado pela impessoalidade nas relações. Os custos derivados da existência desses arranjos são igualmente divididos entre os interessados em sua existência.

Nem todos os intercâmbios, entretanto, envolvem ativos homogêneos. O caso clássico descrito pela perspectiva da governança é aquele em que bens 
dotados de um determinado grau de especificidade são transacionados entre os agentes. Nesse caso, dá-se o que Williamson (1985) denomina "transformação fundamental”: a especialização produtiva cria uma relação de dependência bilateral entre as partes. Conforme já observado anteriormente, o processo de diferenciação progressiva diminui as possibilidades de comercialização por meio dos mercados padrão.

É natural que tampouco sejam suficientes as informações disponíveis nesses mercados. Afinal, estas dizem respeito, basicamente, aos ativos ali transacionados. Em outras palavras, as estruturas responsáveis pela decodificação e pelo fornecimento dos dados de bens homogêneos não disponibilizam uma avaliação precisa do valor derivado da existência de uma quase renda. Cabe aos agentes, por meio da instituição de estratégias alternativas, obter esses dados. Soluções não faltam: a contratação de especialistas (COASE, I937, p. 390) ou o estabelecimento de arranjos especializados, como um departamento no interior da firma, são possibilidades.

A noção de custo de transação, assim, está diretamente ligada à capacidade de determinação do melhor uso possível dos recursos à disposição (DEMSETZ, 20II). À medida que há um aumento da especificidade de um ativo, aumentam também os custos individuais de obtenção dos preços relevantes. O motivo é simples: as estruturas burocráticas dedicadas a fornecer a informação nos mercados típicos de concorrência perfeita perdem parte de sua relevância. Descobrir o quanto cada indivíduo interessado deseja pagar por um ativo passa a depender do estabelecimento de arranjos alternativos, especializados na busca desses dados.

Por isso, espera-se que nem todos os agentes sejam capazes de identificar oportunidades de negócio no cenário descrito pela perspectiva da governança. Quando os custos de obtenção dos preços relevantes forem proibitivos, será impossível dimensionar os benefícios potenciais do investimento em ativos específicos. O problema padrão analisado por Oliver Williamson, entretanto, depende do estabelecimento de uma relação cooperativa entre os agentes. Como se daria a aproximação entre os indivíduos em um mundo em que obter informação custa caro?

De fato, ao identificar uma oportunidade de negócio, um agente pode depender do engajamento de outros indivíduos para materializá-la. Nada garante, porém, que as outras partes consigam delimitar a recompensa derivada dessa relação cooperativa. Pode ser necessário que o agente capaz de visualizar a oportunidade ofereça incentivos para que os outros aceitem participar desse esforço. Mais especificamente, que ele proponha uma determinada remuneração em 
troca da realização de investimentos específicos e, consequentemente, da geração de quase renda.

Quando se assume a possibilidade de que os agentes atuem de forma oportunista (WILLIAMSON, I993b), é possível que, nesse caso, a informação relativa aos preços relevantes não seja integralmente transferida. Com isso, haveria um desalinhamento entre as contribuições individuais e as respectivas recompensas. A captura de uma parcela desproporcional da quase renda, em outras palavras, pode ocorrer mesmo em relações estáveis. Trata-se de um importante desdobramento analítico, quando se tem em conta a ênfase dada pela perspectiva da governança ao problema do hold up.

O enriquecimento da ideia de custo de transação, em resumo, adiciona uma nova dimensão ao estudo da estratégia. Não basta o alinhamento eficiente das estruturas de governança; obter a informação relevante também é fundamental. As próximas seções demonstram a importância da nova sociologia econômica para a demonstração desse problema. Serão discutidos o papel das redes na disseminação de informação e os efeitos de sua existência sobre os custos de descoberta dos preços relevantes.

\section{O ENRAIZAMENTO SOCIAL E O AMBIENTE INSTITUCIONAL}

Duas conclusões principais são encontradas nas páginas anteriores. A primeira delas é a de que os custos de descoberta dos preços relevantes crescem à medida que há um aumento da especificidade dos ativos. Ademais, argumentase que a dificuldade de obtenção dessa informação pode levar a um desalinhamento entre as contribuições individuais em um esforço cooperativo e a respectiva recompensa. Em outras palavras, um agente pode se apropriar de uma parte da quase renda sem recorrer à quebra contratual, desde que a outra parte seja incapaz de delimitar aquilo que lhe cabe na relação.

Entender a contribuição que a ideia de enraizamento traz para o entendimento do problema descrito anteriormente exige algumas ressalvas. Trata-se de uma noção que, assim como a de "custo de transação", recebeu inúmeras interpretações (ZUKIN; DIMAGGIO, I990; SMELSER; SWEDBERG, I994; BECKERT, 2007). É fundamental salientar, ademais, que Williamson (I99Ib, 2002) oferece a sua própria interpretação para a inserção do enraizamento em seu arcabouço teórico. A visão da perspectiva da governança sobre a conveniência de uma integração teórica não pode ser ignorada. 
Em resposta às críticas dos sociólogos, Williamson (I99Ib, 2002) argumenta que aspectos referentes ao enraizamento são apreendidos pela perspectiva da governança por meio da consideração do ambiente institucional em que ocorrem os intercâmbios. Indivíduos baseados em sociedades coesas tenderiam a evitar litígios, preferindo a negociação bilateral. O enraizamento ajudaria a determinar os custos relativos de governança das transações, partindo-se da hipótese do alinhamento eficiente.

É importante sublinhar que o próprio Williamson (2000, p. 597) reconhece que sua preocupação reside em um nível analítico inferior àquele necessário para a plena apreensão do enraizamento. Sua insistência em associar essa ideia ao pensamento de Douglass North, porém, distorce o significado da contribuição dos sociólogos. Ao equivaler o enraizamento ao ambiente institucional, a perspectiva da governança desconsidera o processo de construção de confiança entre as partes ${ }^{8}$. Da mesma forma, ignora a possibilidade do uso de estratégias baseadas em uma lógica não econômica para a obtenção de objetivos econômicos.

Alongar-se em torno das objeções de Granovetter (I985) às ideias de Williamson é desnecessário. É suficiente lembrar que, segundo aquele, a principal deficiência da perspectiva da governança está na capacidade que concede aos arranjos organizacionais de mitigar os problemas relacionados à governança econômica. Longe de se concentrar na análise das relações concretas estabelecidas entre os indivíduos, Williamson prefere lançar o seu olhar sobre as características dos ativos transacionados.

Isso não significa, obviamente, que Granovetter considere trivial o problema da organização econômica. Em seu artigo de i985, o autor reconhece que ações oportunistas seguirão existindo em um mundo em que as redes de relacionamento não são generalizadas. Além disso, Granovetter (I985, p. 49I) lembra que percalços poderão ocorrer mesmo em relações caracterizadas por um longo histórico de convivência. A garantia da ordem, portanto, seria algo mais complexo que a prescrição de Williamson sugere.

Um embate em torno da hipótese do alinhamento eficiente, de qualquer maneira, fornece uma representação incompleta da crítica sociológica à perspectiva da governança. Garantias são necessárias para a realização de diversas transações; o próprio Granovetter reconhece a ocorrência de trapaça. Mais importante para o debate é a avaliação do caráter generalizador que Williamson (2002) concede ao enraizamento, equivalendo a noção a uma influência homogênea

O protagonismo concedido ao oportunismo em seu modelo faz com que Williamson (I993a) considere desnecessário o debate acerca da existência de confiança para a análise da organização econômica. Apesar de concordar que exageros na adoção de uma abordagem comportamental calculativa são contraproducentes, o autor prefere o uso do termo "risco". 
sobre um grupo humano. Ou seja, estende ao enraizamento a concepção supersocializada a qual já havia usado para descrever a firma anteriormente.

Ao equivaler o enraizamento ao conjunto de regras informais de uma sociedade, Williamson dá a entender que os indivíduos obedecerão a um conjunto de valores compartilhados simplesmente porque estes se consolidaram ao longo do tempo. Práticas sociais, no entanto, podem diferir consideravelmente de acordo com o grupo analisado. É justamente o papel dessa diversidade para a explicação do problema distributivo aqui estudado o foco da próxima seção.

\section{REDES E A OBTENÇÃO DE INFORMAÇÃO}

A seção anterior demonstra que a tentativa de Williamson de integrar a noção de enraizamento à perspectiva da governança apresenta dois problemas:

- A associação entre o ambiente institucional e o enraizamento considera apenas o efeito sobre os custos de governança relativos em uma sociedade.

- A própria concepção de enraizamento adotada por Williamson é imprecisa, pois ela tanto superestima o papel das regras informais quanto se limita às motivações e às estratégias econômicas dos agentes.

A busca por alternativas, assim, é necessária. Tendo em vista o problema da descoberta dos preços relevantes aqui discutido, há elementos na contribuição proporcionada pela nova sociologia econômica que auxiliam o seu esclarecimento. Os desdobramentos da crítica de Granovetter à perspectiva da governança, que originariam a abordagem estrutural da nova sociologia econômica (GRANOVETTER, 2005; UZZI, I996; MIZRUCHI, 2009), permitem a proposição de hipóteses para o estudo da apropriação de valor em relações cooperativas.

O encaminhamento dessa discussão, porém, exige um lembrete. É preciso evitar uma idealização da ideia de enraizamento, opção de muitos sociólogos. Afinal, como lembra Hinrichs (2000), a existência de estruturas sociais não leva ao abandono dos preços na tomada de decisões na esfera econômica. Pelo contrário, trata-se de um parâmetro considerado em praticamente todas as transações. A questão relevante, nesse caso, é descobrir como os indivíduos obtêm esse dado.

Daí a importância da adição das redes a qualquer cenário que se proponha a estudar a organização econômica. O reconhecimento de que a informação relevante para a ação econômica não é gratuita exige uma abordagem que supere a ideia de atomização dos agentes. Se a sua obtenção demanda tempo e recursos, os indivíduos se organizarão, encontrando alternativas para o fornecimento. 
Ademais, a hipótese de que, por causa dos custos, determinados agentes terão acesso a informações indisponíveis a outros levanta um questionamento acerca das motivações por trás de sua transferência unilateral.

Qual é o papel do enraizamento, então, no problema da apropriação do valor? Conforme lembra Granovetter (2005, p. 35), a existência de enraizamento social implica o reconhecimento de que a ação econômica está ligada a ações ou a instituições cujos conteúdo, objetivos e processos são não econômicos. No caso em tela, o principal desdobramento dessa conclusão é o de que a participação em redes, uma estratégia ignorada em cenários caracterizados pela atomização dos agentes, ajuda a explicar a magnitude dos custos de descoberta dos preços relevantes incorridos pelos agentes.

Proposições mais específicas podem ser derivadas. Primeiramente, ceteris paribus, a participação em uma rede contribui para a diminuição dos custos de descoberta dos preços relevantes. Os motivos se relacionam com a própria essência dessas estruturas. $\mathrm{O}$ fato de transcenderem as organizações e as instituições convencionais (MIZRUCHI, 2009, p. I35) faz com que suas potencialidades e limitações não coincidam com aquelas encontradas nos arranjos que decodificam dados de uso geral, como aqueles existentes nos mercados de concorrência perfeita.

Características específicas de uma rede também contribuem para os resultados colhidos pelos agentes em um esforço cooperativo. Por exemplo, o grau de uniformidade entre as informações em posse de seus integrantes ajuda a determinar a magnitude desses custos. Quanto mais diversos os dados detidos por um determinado grupo, maiores as possibilidades de identificação de oportunidade de negócio e de delimitação da recompensas correspondentes a um esforço cooperativo. Não por acaso, laços fracos (GRANOVETTER, I973, I983) constituem uma importante fonte de informação às partes.

Espera-se, ademais, que a transferência gratuita de informações indisponíveis a uma das partes ocorra com maior facilidade quando ambos os agentes participarem de uma mesma rede densa. Isso se deve, antes de tudo, à maior publicidade de um padrão de "bom comportamento" entre seus participantes (GRANOVETTER, 2005, p. 34), o que desencorajaria a trapaça. O compartilhamento de crenças comuns entre as partes, da mesma forma, tornaria essa prática algo natural para as partes, independentemente da possibilidade de coerção futura.

Redes muito densas, por sua vez, embora forneçam maior previsibilidade nas relações entre seus membros, podem inviabilizar a obtenção de informação relevante. De acordo com Uzzi (I996, p. 685), a combinação entre os incentivos fornecidos pelo mercado e as vantagens decorrentes da participação em uma rede oferece melhores possibilidades de adaptação aos agentes econômicos. A existência dessas estruturas, de fato, apenas evidencia os desvios na caraterização 
do cenário utilizado pelos economistas, e não a sua inexistência. As informações disponibilizadas nos mercados impessoais, além de fornecerem uma referência aos agentes, caracterizam-se pelo baixo custo de obtenção.

Tendo em conta as hipóteses descritas nos últimos parágrafos, é importante lembrar que a existência de enraizamento social não implica, necessariamente, a transferência integral das informações necessárias para a delimitação da quase renda. Um alerta acerca de uma oportunidade de negócio, por exemplo, não precisa estar acompanhado de explicações pormenorizadas sobre suas potencialidades. Conforme lembra Kirchbaum (2009, p. 313), a difusão de informação em uma rede pode ser heterogênea, dependendo da natureza dos laços existentes entre os indivíduos.

Em suma, estruturas de governança caracterizadas como idênticas pela perspectiva da governança podem abrigar, em seu cotidiano, padrões de distribuição absolutamente diversos. As chaves para a compreensão dessa heterogeneidade são: I. a avaliação da inserção dos indivíduos no entorno social, com atenção para os seus múltiplos pontos de contato, independentemente do grau de formalização organizacional; 2. o entendimento da dinâmica de interação entre cada um desses pontos de contato entre os indivíduos em uma dada sociedade, especialmente quanto à capacidade de fornecimento de informação aos agentes.

Antes do encerramento dessa seção, dois lembretes são válidos. Em primeiro lugar, o raciocínio aqui apresentado assume que os agentes optarão por alinhar contribuições e recompensas sempre que tiverem acesso a toda a informação relevante. A distribuição dos resultados econômicos derivados da cooperação humana, entretanto, não obedece exclusivamente à lógica apresentada nas últimas páginas. O próprio inspirador da noção de enraizamento social, Karl Polanyi, representa um exemplo de incansável descrição dessa realidade`.

Em segundo lugar, caso o interesse analítico se concentre no estudo da adaptação eficiente, é indiferente o fornecimento de incentivos por meio de uma relação impessoal ou por laços fortes. Desde que haja motivos para a transferência de, ao menos, parte da informação relevante, as chances de estabelecimento de uma relação cooperativa são consideráveis. O conteúdo aqui discutido busca contribuir para uma avaliação que vá além da mera alocação dos recursos. Afinal, no estudo da estratégia, é importante saber quanto cabe aos agentes em sua atividade na esfera econômica.

9 É interessante observar que, aos olhos de um neoinstitucionalista como North (I977), a considerável diversidade descrita por Polanyi em seus estudos sobre sociedades humanas pode ser explicada com argumentos inspirados na lógica dos custos de transação. 


\section{CONSIDERAÇÕES FINAIS}

Ao apresentar uma retrospectiva de sua atividade intelectual, Williamson (20II) enumera citações-chave para a construção teórica que o notabilizou. Uma delas, pertencente a um texto de Frank Knight (I94I apud WILLIAMSON, 200I, p. 3$)^{\mathrm{IO}}$, diz que "os homens, em geral, e dentro de limites, desejam se comportar economicamente, a fim de tornar suas atividades e sua organização eficiente, e não um desperdício" ${ }^{\text {II. }}$. A perspectiva da governança, nesse sentido, representa um esforço de compreensão da lógica por trás dessa busca constante por eficiência.

Este trabalho, por sua vez, discute os limites aos quais se refere Knight. Ao longo das últimas páginas, buscou-se demonstrar que as estruturas de governança descritas por Williamson podem revelar padrões de distribuição de valor distintos daqueles previstos pela perspectiva da governança. Em outras palavras, a hipótese do alinhamento eficiente, quando analisada a partir de uma concepção mais realista dos mercados - e de seus participantes -, possibilita a avaliação da heterogeneidade.

Para tanto, o desenvolvimento da nova sociologia econômica é fundamental. Desde a publicação de seu manifesto fundador (GRANOVETTER, I985), essa corrente teórica tem proporcionado uma rica contribuição teórica. Nela, chamam a atenção tanto as críticas aos pontos cegos pertencentes à análise econômica quanto o caráter propositivo de seus trabalhos. O presente estudo, ao integrar a abordagem estrutural à perspectiva da governança, beneficia-se do espírito crítico trazido pela reflexão sociológica.

Finalmente, as ideias aqui apresentadas buscam demonstrar que a convivência entre a visão dos sociólogos e aquela defendida pelos neoinstitucionalistas econômicos é possível. Swedberg (2004, p. I6) observa que, após o interesse inicial, os sociólogos abandonaram o debate acerca dos custos de transação. Este artigo rema contra a correnteza e vai além das controvérsias tradicionais. $\mathrm{O}$ enriquecimento de noções como a de "custo de transação" depende fortemente de uma visão multidisciplinar. Que prospere, assim, o diálogo entre as duas abordagens.

ro O texto de Frank Knight em questão, publicado no Journal of Political Economy, é intitulado "Review of Melville J. Herskovits 'Economic Anthropology'”.

II A citação original, em inglês, é a seguinte: "men in general, and within limits, wish to behave economically, to make their activities and their organization 'efficient' rather than wasteful". 


\section{BEYOND ECONOMIZING: SOCIAL NETWORKS AND VALUE APPROPRIATION IN COOPERATIVE RELATIONSHIPS}

\section{ABSTRACT}

This theoretical work investigates the role of social networks in explaining value appropriation in cooperative relationships. The governance perspective (WILLIAMSON, I985, I996) uses a scenario composed by atomized agents to explain economic organization. Under this view, individuals can establish ex ante the benefits of participating in a cooperative relationship. Consequently, they can mitigate threats of opportunist behavior. The present work demonstrates that, due to the existence of specific assets, the governance perspective characterizes markets imprecisely. More specifically, it argues that the existence of positive transaction costs makes it difficult to obtain relevant information which is used to determine the value created in a cooperative relationship. Consequently, a misalignment between relative contributions and rewards may occur. This paper provides an explanation, based on new economic sociology (GRANOVETTER, I985, 2005; UZZI, I996) for the process of gathering information and the reasons which determine its transference among individuals. The main conclusions are: I. hold up does not represent the only threat of opportunist behavior in a cooperative relationship; 2 . the transference of information helps to explain social embeddedness; 3 . being part of a network is a source of reducing the costs of discovering relevant information; 4 . the existence of embedded networks explains the free transfer of information among their members. The reasoning developed here intends to clarify the relationship among individuals and their interaction space where assets are exchanged. It allows a more realistic approach to the architecture of markets, a topic which has not received attention from economists. It also provides tools for interpreting the existence of heterogeneous patterns of distribution of value in cooperative relationships.

\section{KEYWORDS}

Strategy; Transaction costs; Embeddedness; Opportunism; Networks. 


\section{MÁS ALLÁ DEL ECONOMIZING: LAS REDES SOCIALES Y LA APROPIACIÓN DE VALOR EN RELACIONES COOPERATIVAS}

\section{RESUMEN}

Este trabajo teórico investiga el papel de las redes sociales para explicar la apropiación de valor en relaciones cooperativas. La perspectiva de la gobernación (WILLIAMSON, I985, I996) utiliza un escenario compuesto por agentes atomizados para explicar la organización económica. Bajo este abordaje, los individuos pueden determinar ex ante las ventajas de participar en una relación cooperativa. En consecuencia, son capaces de mitigar las amenazas de comportamiento oportunista. El presente texto demuestra que, debido a la existencia de activos específicos, la perspectiva de la gobernación caracteriza los mercados de modo impreciso. Más especificamente, sostiene que la existencia de costos de transacción positivos dificulta la obtención de la información necesaria para determinar el valor creado en una relación cooperativa. El resultado: un desalineamiento entre las contribuciones relativas y las recompensas derivadas de este esfuerzo. Este trabajo ofrece una explicación, inspirada en la nueva sociología económica (GRANOVETTER, I985, 2005; UZZI, I996) para el proceso de obtención de información y los motivos que determinan su transferencia entre los agentes. Las conclusiones son: I. el hold up no es la única amenaza de comportamiento oportunista en una relación cooperativa; 2. la transferencia de información está relacionada con el embeddedness; 3. la participación en una red es una forma de reducir los costos de descubrimiento de la información necesaria; 4. la existencia de redes enraizadas explica la transferencia gratuita de informacion entre sus participantes. El presente texto busca esclarecer la relación entre los agentes y su espacio de interacción. Además, proporciona herramientas para la interpretación de la existencia de patrones heterogéneos de distribución de valor en relaciones cooperativas.

\section{PALABRAS CLAVE}

Estrategia; Costos de transacción; Embeddedness; Oportunismo; Redes.

\section{REFERÊNCIAS}

ABRAMOVAY, R. Entre Deus e o diabo: mercados e interação humana nas ciências sociais. Tempo Social, v. I6, n. 2, p. 35-64, nov. 2004.

Entrevista. In: BASTOS, E. R. et al. (Org.). Conversas com sociólogos brasileiros. São Paulo:

Editora 34, 2005. p. 425-436. 
ALCHIAN, A.; DEMSETZ, H. Production, information costs, and economic organization. American Economic Review, v. 62, n. 5, p. 777-795, Dec. 1972.

ARROW, K. J. The organization of economic activity: issues pertinent to the choice of market versus nonmarket allocation. In: The analysis and evaluation of public expenditure: the PPT system. US Joint Economic Committee, 9I st Congress. Ist Session, US Government Printing Office, I969. v. I.

ARRUÑADA, B. The quasi-judicial role of large retailers: an efficiency hypothesis of their relation with suppliers. In: BROUSSEAU, E.; GLACHANT, J.-M. The economics of contracts: theories and applications. Cambridge: Cambridge University Press, 2002. p. 337-357.

BECKERT, J. The great transformation of embeddedness: Karl Polanyi and the New Economic Sociology. Cologne: Max Planck Institute for the Study of Societies, 2007. (MPIfG Discussion Paper 07/I). BLOCK, F. Introduction. In: POLANYI, K. The great transformation: the political and economic origins of our time. Boston: Beacon Press, 200I.

CHEUNG, S. The contractual nature of the firm. The Journal of Law and Economics, v. 26, n. I, p. I-2I, Apr. I983.

COASE, R. H. The nature of the firm. Economica, v. 4, n. I6, p. 386-405, Nov. I937.

. The problem of social cost. Journal of Law and Economics, v. 3, n. I, I960.

DEMSETZ, H. The problem of social cost: what problem? A critique of the reasoning of A. C. Pigou and R. H.Coase. Review of Law and Economics, v. 7, n. I, p. I-I3, 201 I.

ELLIOTT, J. E. Introduction. In: SCHUMPETER, J. The theory of economic development. New Brunswick: Transaction Editions, 2007. p. VII-LIX.

FISCHER, S. Long-term contracting, sticky prices, and monetary policy: comment. Journal of Monetary Economics, v. 3, n. 3, p. I9I-205, July I977.

GHOSHAL, S. Bad management theories are destroying good management theories. Academy of Management Learning and Education, v. 4, n. I, p. 75-9I, Mar. 2005.

GHOSHAL, S.; MORAN, P. Bad for practice: a critique of the transaction cost theory. Academy of Management Review, v. 2I, n. I, p. 13-47, Jan. I996.

GRANOVETTER, M. The strength of weak ties. American Journal of Sociology, v. 78, n. 6, p. I360I380, May I973.

. The strength of weak ties: a network theory revisited. Sociological Theory, v. I, p. 20I-233, I983. Economic action and social structure: the problem of embeddedness. American Journal of Sociology, v. 9I, n. 3, p. 48I-5IO, Nov. I985.

. The impact of social structure on economic outcomes. Journal of Economic Perspectives, v. I9, n. I, p. 33-50, Winter 2005 .

HINRICHS, C. C. Embeddedness and local food systems: notes on two types of direct agricultural markets. Journal of Rural Studies, v. I6, n. 3, p. 295-303, July 2000.

KALDOR, N. The equilibrium of the firm. The Economic Journal, v. 44, n. I73, p. 60-76, Mar. I934. KIRCHBAUM, C. Renascença da indústria brasileira de filmes: destinos entrelaçados? In: MARTES, A. C. B. Redes e sociologia econômica. São Carlos: Editora da UFSCar, 2009. p. 309-335.

KIRCHBAUM, C.; IWAI, T. Teoria dos jogos e microssociologia: avenidas de colaboração. Revista de Administração Contemporânea, v. I5, n. I, p. I38-I57, fev. 20 II.

KLEIN, B. The role of incomplete contracts in self-enforcing relationships. In: BROUSSEAU, E.; GLACHANT, J.-M. The economics of contracts: theories and applications. Cambridge: Cambridge University Press, 2002. p. 59-7I. 
KLEIN, B.; CRAWFORD, R. G.; ALCHIAN, A. Vertical integration, appropriable rents, and the competitive contracting process. Journal of Law and Economics, v. 2I, n. 2, p. 297-326, Oct. I978. MACHER, J.; RICHMAN, B. Transaction cost economics: an assessment of empirical research in the social sciences. Durham: Duke Law School, 2006. (Legal Studies Research Paper Series, n. II5). MENARD, C. On clusters, hybrids, and other strange forms: the case of the French poultry industry. Journal of Institutional and Theoretical Economics, v. I52, n. I, p. I54-I83, Mar. I996.

MIRANDA, B. V.; SAES, M. S. M. Transaction costs, embeddedness and the ex ante distribution of the quasi rent. In: CONFERENCE OF THE INTERNATIONAL SOCIETY FOR THE NEW INSTITUTIONAL ECONOMICS, I5., 20II, Palo Alto. Proceedings... Palo Alto, 20Iı. Disponível em: $<$ http://extranet.isnie.org/uploads/isnie2oII/miranda_saes.pdf>. Acesso em: 3 jul. 20 II.

MIZRUCHI, M. Análise de redes sociais: avanços recentes e controvérsias atuais. In: MARTES, A. C. B. Redes e sociologia econômica. São Carlos: Editora da UFSCar, 2009. p. I3I-I59.

NICKERSON, J.; YEN, J. Economizing e strategizing. Disponível em: <http://organizationsandmarkets.files.wordpress.com/2009/09/nickerson-and-yen-economizing-and-strategizing.pdf>. Acesso em: mar. 20II.

NORTH, D. Markets and other allocation systems in history: the challenge of Karl Polanyi. Journal of European Economic History, v. 6, n. 3, p. 703-716, Winter I977.

Instituciones, cambio institucional y desempeño económico. México: Fondo de Cultura Económica, I993.

PORTER, M. Competitive advantage: creating and sustaining superior performance. New York: The Free Press, I985.

Como as forças competitivas moldam a estratégia. In: MONTGOMERY, C.; PORTER, M. (Ed.). Estratégia: a busca da vantagem competitiva. Rio de Janeiro: Campus, I998. p. II-27.

ROBINSON, J. The economics of imperfect competition. London: Macmillan, I933.

SHELANSKI, H.; KLEIN, P. Empirical research in transaction costs economics: a review and assessment. Journal of Law, Economics and Organization, Individualism and Economic Order, v. II, n. 2, I995.

SMELSER, N.; SWEDBERG, R. The sociological perspective on the economy. In: (Org.). The handbook of economic sociology. New York: Russel Sage Foundation, I994. p. 3-25.

STIGLER, G. J. Imperfections in the capital market. Journal of Political Economy, v. 75, p. 287-292, June I967.

SWEDBERG, R. Sociologia econômica: hoje e amanhã. Tempo Social, v. I6, n. 2, p. 7-34, 2004.

UZZI, B. The sources and consequences of embeddedness for the economic performance of organizations: the network effect. American Sociological Review, v. 6I, n. 4, p. 674-698, Aug. 1996.

VINHA, V. Polanyi e a nova sociologia econômica: uma aplicação contemporânea do conceito de enraizamento social. Econômica, v. 3, n. 2, p. 207-230, dez. $200 \mathrm{I}$.

WILKINSON, J. A contribuição da teoria francesa das convenções para os estudos agroalimentares: algumas considerações iniciais. Ensaios FEE, v. 20, n. 2, p. 64-80, I999.

WILLIAMSON, O. The economic institutions of capitalism. New York: The Free Press, I985.

Strategizing, economizing and economic organization. Strategic Management Journal, v. I2, p. 75-94, Winter i991а.

. Comparative economic organization: the analysis of discrete structural alternatives. Administrative Science Quaterly, v. 36, n. 2, p. 269-296, June i99ib. 
WILLIAMSON, O. Calculativeness, trust and economic organization. Journal of Law and Economics, v. 36, n. I, p. 453-486, Apr. I993a.

. Opportunism and its critics. Managerial and Decision Economics, v. I4, n. 2, p. 97-107, Mar./Apr. ı993b.

. The mechanisms of governance. Oxford: Oxford University Press, I996.

. The New Institutional Economics: taking stock, looking ahead. Journal of Economic Literature, v. 38, p. 595-6r3, Sept. 2000.

. The theory of the firm as governance structure: from choice to contract. The Journal of Economic Perspectives, v. I6, n. 3, p. I7I-I95, Summer 2002.

. The economics of governance. The American Economic Review, v. 95, n. 2, p. I-I8, May 2005 .

. Transaction costs economics: an overview. Disponível em: <http://organizationsandmarkets. files.wordpress.com/2009/09/williamson-o-transaction-cost-economics-an-overview.pdf>. Acesso em: mar. 20 II.

ZUKIN, S.; DIMAGGIO, P. Introduction. In: (Ed.). Structures of capital: the social organization of the economy. Cambridge: Cambridge University Press, I990. p. I-36. 